\title{
Knowledge and attitude towards plagiarism: a comparative study of students from medical and non-medical fields
}

\author{
Roha S Memon ', Mahrukh M Ali ${ }^{1}$, Marium Zafar ${ }^{1}$, Asim Shaikh \\ ${ }^{1}$ Medical Student, Dow University of Health Sciences, Karachi, Sindh, Pakistan \\ Keywords: global health \\ https://doi.org/10.29392/joghr.3.e2019067
}

\section{Journal of Global Health Reports}

Vol. 3, 2019

\begin{abstract}
Background
Research has become a crucial part of restorative sciences. Yet, research ethics are sometimes bypassed. One of the research ethical misconducts, plagiarism has always been prevalent. Studies published on plagiarism have seen an increase recently but mostly they are from the developed part of the world and output from developing countries like Pakistan is low. This study, therefore, aims to compare the knowledge, attitudes, and practices of students from medical and non-medical fields towards plagiarism from different institutions in Karachi, Pakistan.
\end{abstract}

\begin{abstract}
Methods
We conducted an eight-week cross-sectional study in January 2017 in Karachi, Pakistan with 412 undergraduate students of ages 18 and above, using convenience sampling to assess their knowledge, attitudes, and practices regarding plagiarism. The questionnaire was divided into three parts, each focusing on knowledge and its source, attitudes, and practices of an individual towards plagiarism. Chi-squared tests were applied to compare the aforementioned factors of participants belonging to the medical field with those from non-medical fields.
\end{abstract}

\begin{abstract}
Results
A majority of individuals ( $\mathrm{n}=288,74.6 \%)$ were aware of the research ethics and had heard about the term plagiarism $(n=353,91.5 \%)$. More than half of the individuals $(n=235$, $60.9 \%)$ had experience with researches. An overwhelming majority of individuals $(n=365$, 94.6\%) considered it important to discuss issues like plagiarism in research ethics. Almost half of them ( $n=186,48.2 \%)$ plagiarized unintentionally due to lack of knowledge and learned about it later. Majority of the individuals $(n=332,86 \%)$ thought plagiarism could be avoided and many ( $n=303,78.5 \%)$ believed that authors who plagiarize deserve punishment. Statistically significant differences were found to exist when knowledge, attitude, and practices were compared between medical and non-medical students. Medical students were more aware of the research ethics than non-medical students $(P=0.001)$. Significantly more medical students considered it important to discuss issues like plagiarism in research ethics than non-medical students $(P=0.011)$ and did not believe that plagiarism is justified for short deadlines $(P<0.001)$. More medical students had experience with research than non-medical students $(P=0.003)$ and a majority of medical students considered plagiarism as stealing $(P<0.001)$.
\end{abstract}

\section{Conclusions}

Majority of the individuals were aware of plagiarism and showed a negative attitude towards its practice. The practice of plagiarism was associated with a lack of knowledge and awareness regarding this misconduct. Medical and non-medical students had differing opinions with medical students having a more negative attitude towards plagiarism owing to their greater knowledge and experience with researches. Academic integrity, provision of plagiarism detection tools and emphasis on research ethics are some of the areas that institutions should work on to reduce plagiarism.

Research has assumed a crucial part in the advancement and development of restorative sciences. In this period of proof-based prescription, distribution of refreshed writing is viable to patient care and to further major discoveries in the field of medicine. Research is not only vital to medicine but also to a number of other fields. However, it's unfortunate that basic ethics of research are sometimes bypassed. Plagiarism has been prevalent, ${ }^{1}$ particularly due to easy ac- cess available to several original studies via the internet. ${ }^{2}$ Defined as the practice of taking someone else's work or ideas and passing them off as one's own, ${ }^{3,4}$ plagiarism is a serious offence due to the negation of contributions of original writers, it has proven to be severely problematic. ${ }^{5,6}$

Recently, a number of studies have been published on research ethics but those are mostly from the developed part of the world where research ethics are taught at the under- 
Table 1. Scenario based question for testing identification of plagiarism

Scenario 1

Original source: With advances in polymer synthesis, electronics and micro/nanofabrication, contact lens sensors can be produced to quantify the concentrations of many biomolecules in ocular fluids. ${ }^{12}$

Author's version: Farandos NM, et al, believes that certain advances in polymer synthesis and related technologies can help

us quantify the concentrations of many biomolecules in ocular fluids by virtue of the development of contact lens sensors. 12

Yes

No

\section{Is author's \\ version \\ plagiarized?}

Original source: With advances in polymer synthesis, electronics and micro/nanofabrication, contact lens sensors

can be produced to quantify the concentrations of many biomolecules in ocular fluids. ${ }^{12}$

Author's version: I believe that certain advances in polymer synthesis, electronics and micro/nanofabrication,

Yes

No graduate level. In comparison, the research output on research ethics focusing especially on plagiarism from developing countries including Pakistan is low. ${ }^{7}$ Ghias's survey ${ }^{5}$ on general disregard of research ethics in Pakistani medical students reported a high frequency of medical students involved in copying work from online published sources, seniors, class fellows with or without their permission, fabrication of data to present desirable outputs, forging professors' signatures, faking health certificates, etc.

Although plagiarism detection software is advancing 8,9 and there has been an increase in the number of plagiarized papers being recognized and withdrawn from the journals, there is a lack of awareness about their existence. ${ }^{10}$ A clear absence of accentuation by establishments featuring the issue has been cited as one of the significant explanations behind widespread plagiarism. ${ }^{7}$

Plagiarism is not only repeatedly opted by medical peers ${ }^{11}$ but also other professional students. However, no such research has been conducted highlighting this fact and establishing a comparison between medical and non-medical students of this misconduct. The purpose of this study was to fill that gap in the assessment of plagiarism and explore the attitudes towards plagiarism amongst medical students and compare it with students from other professional branches including engineering, arts, commerce, etc.

\section{METHODS}

In January-February 2017, we received an approval from the Institutional review board of Dow University of Health Sciences to conduct an eight-week cross-sectional study for the assessment of the knowledge and attitudes of Undergraduate students in Karachi, Pakistan towards plagiarism in researches. With a confidence level of $95 \%$ and an outcome factor frequency of $50 \%$, a sample size of 384 was calculated. Using convenience sampling, we interviewed 412 students. Considering that 18 (4.3\%) out of 412 interviewees refused to take part in the study and a further 7 (1.6\%) left the questionnaires incomplete which were thus discarded, the cooperation rate came out to be $94.1 \%$.

All undergraduate students of Karachi irrespective of their fields of study were allowed to participate. Since all participants of our study were 18 years old or above, written consent was taken only after ensuring the anonymity of their identities and confidentiality of their responses. Age and socioeconomic restrictions such as household income and enrollment in public/private sector universities were not placed. The only restrictions placed were academic status which should be undergraduate and city of residence which had to be Karachi. The questionnaire was developed according to the objective and design of our study by an equal contribution from all the authors. It consisted of 28 questions and was divided into three parts. The first part focused on the knowledge of the interviewees about plagiarism in researches and included questions regarding awareness of research ethics, the term plagiarism and the different tools used to detect plagiarism. Two scenario-based questions ${ }^{12}$ were also included for better assessment of the knowledge as shown in Table 1. One was plagiarized while the other was not. The second and the third section of the questionnaire involved attitude and practice-related questions respectively. Attitudes were assessed using questions related to the personal views of students towards the importance of plagiarism-proof writing and the punishments associated with cases of non-compliance. Practice-related questions considered the reasons of plagiarizing, if done in the past, together with the measures taken to eradicate plagiarism, if any.

All the authors collected data using a pre-coded questionnaire by conducting face-to-face interviews. Certain measures were taken to avoid possible biases. The interviewers avoided engaging in mundane conversations, had prepared explanations of the questions and set a time for the participants. This aimed at reducing interviewer and instruction bias. Response bias was reduced by ensured anonymity. The time frame for the practice questions was 1 year which minimized recall bias. Using Statistical Package for the Social Sciences (SPSSver. 23; IBM, Armonk, NY, USA), $\chi-2$ test was applied to compare the responses of medical and non-medical students to find possible statistical correlations.

\section{RESULTS}

A total of 385 students, enrolled in medical and non-medical universities completed the questionnaire, out of which 145 (37.7\%) were males and 240(62.3\%) were females. 206(53.4\%) students were enrolled in medical universities while 179 (46.4\%) belonged to non-medical universities. The mean age of the students was $21.1 \pm 1.8$. Students en- 
Table 2. Demographics of the population.

\begin{tabular}{|c|c|}
\hline Variables & Values $(n=385)$ \\
\hline \multirow[t]{2}{*}{ Mean Age } & $21.130 \pm 1.831$ years \\
\hline & Male=145 (37.7\%) \\
\hline \multirow[t]{2}{*}{ Gender } & Female $=240(62.3 \%)$ \\
\hline & Medical=206 (53.4\%) \\
\hline \multirow[t]{5}{*}{ Faculty } & Non-medical=179 (46.4\%) \\
\hline & $\mathrm{MBBS}=191$ \\
\hline & $\mathrm{BDS}=8$ \\
\hline & Doctor of Pharmacy=7 \\
\hline & $\mathrm{BBA}=64$ \\
\hline \multirow[t]{9}{*}{ Field of Study } & Arts $=29$ \\
\hline & Engineering $=49$ \\
\hline & Computer Science= 17 \\
\hline & Chartered Accountancy $=4$ \\
\hline & $\mathrm{Law}=16$ \\
\hline & DUHS=168 \\
\hline & $J S M U=16$ \\
\hline & $\mathrm{KMDC}=6$ \\
\hline & Ziauddin University=11 \\
\hline \multirow[t]{5}{*}{ Institute } & Karachi University=73 \\
\hline & NED University $=61$ \\
\hline & $\mathrm{IBA}=36$ \\
\hline & Iqra University=10 \\
\hline & Tabani's Institute of accountancy $=4$ \\
\hline
\end{tabular}

DUHS - Dow University of Health Sciences, JSMU - Jinnah Sindh Medical University, KMDC - Karachi Medical and Dental College, IBA - Institute of Business Administration

rolled in medical universities belonged to Dow University of Health Sciences (168 students), Jinnah Sindh Medical University (16 students), Karachi Medical and Dental College (6 students), and Ziauddin University Hospital (11 students), among which 191 students were enrolled in MBBS program, 8 students in BDS program and 7 students were doing Doctor of Pharmacy. Students enrolled in non-medical universities belonged to Karachi University (73 students), NED University (61 students), Institute of Business Administration (36 students), Iqra University (10 students), and Tabani's School of Accountancy (4 students), among which 64 students were enrolled in BBA program, 29 students in Arts, 49 students in engineering, 17 students in Computer Science, 4 in Chartered Accountancy, and 16 in Law program. Demographics are shown in Table 2.

A vast majority of individuals $(n=288,74.6 \%)$ were aware of research ethics and had heard about the term plagiarism $(n=353,91.5 \%)$. Majority of individuals $(n=335,86.8 \%)$ were aware of the term "referencing" and knew its importance. More than two-thirds of the individuals identified the authentic ie, not plagiarized paragraph $(n=262,67.9 \%)$, and plagiarized paragraph $(\mathrm{n}=267,69.2 \%)$.

An overwhelming majority of individuals $(n=365,94.6 \%)$ considered it important to discuss issues like plagiarism in research ethics. Almost half of the individuals $(n=180$, $48.6 \%$ ) believed that self-plagiarism was plagiarism and more than one-third $(n=136,35.5 \%)$ believed that they work in plagiarism-free environments. Almost one-third of the individuals $(n=125,32.4 \%)$ held the opinion that plagiarism could be justified by short deadlines, and 154 (39.9\%) felt tempted to commit plagiarism because everyone else was doing it. Almost all the individuals $(n=332,86 \%)$ thought plagiarism could be avoided and 303 (78.5\%) believed that authors who plagiarize deserve punishment. 271 (70.2\%) individuals supposed that beginners in the field of research should be forgiven for plagiarism since they're at the early stage of learning, while a majority $(n=342,88.6 \%)$ considered plagiarism as stealing.

More than half of the individuals ( $n=235,60.9 \%)$ had experience with researches. Almost half of them $(n=186$, $48.2 \%$ ) plagiarized unintentionally due to lack of knowledge and learned about it later. Majority $(n=238,61.7 \%)$ considered checking their articles for plagiarism before sending it to a journal. More than one-third of the individuals $(n=138$, $35.8 \%$ ) used freely available online tools to detect plagiarism in their research papers, 150 (38.9\%) used to get their articles reviewed for plagiarism by the review board of your institute before sending it to a journal. Only 91 (23.6\%) plagiarized because their institute did not have a plagiarism policy, and 238 (61.7\%) copied a friend's or a colleague's work with his permission.

$\chi-2$ tests were conducted and knowledge of, attitude towards, and practices regarding research ethics and plagiarism of medical students were compared with those of nonmedical students. Medical students were more aware of the research ethics than non-medical students $(P=0.001)$. Majority of the medical students identified the authentic paragraph and plagiarized paragraph $(P=0.005$, and $P<0.001$, re- 
spectively). When the attitudes were compared, significantly more medical students considered it important to discuss issues like plagiarism in research ethics than non-medical students $(P=0.011)$ and did not believe that plagiarism is justified for short deadlines $(P<0.001)$. Non-medical students felt tempted to plagiarize because everyone else was doing it more than medical students $(P<0.001)$, and a majority of medical students considered plagiarism as stealing $\left({ }^{*} \mathrm{P}<{ }^{*} 0.001\right)$. Furthermore, statistically significant differences were also found when comparing the practices of medical and non-medical students. More medical students had experience with research than non-medical students $\left({ }^{*} \mathrm{P}=* 0.003\right)$. Significantly more non-medical students plagiarized unintentionally due to lack of knowledge and learnt about it later than medical students $(P<0.001)$. However, more non-medical students used online plagiarism detection tools to check plagiarism in their papers $(P<0.001)$ and get their articles reviewed for plagiarism by the review board of their institute before sending it to a journal $(P=0.036)$. Statistically, a significant difference was found to exist between the groups when they were asked if they had ever plagiarized because their institute did not have a plagiarism policy $(P<0.001)$. More non-medical students had copied a friend's or a colleague's work with his permission than non-medical students $(P<0.001)$. The comparative results with their significant differences have been shown in Table 3.

\section{DISCUSSION}

Our principal finding was that a majority of the participants had significant knowledge of the term plagiarism and the importance of referencing and considered its discussion vital in research ethics. These results are inconsistent with another study conducted in Pakistan which indicated a significant lack of the knowledge of referencing and plagiarism among students and faculty members of medical colleges. ${ }^{7}$ Similarly, another study on dental and medical professionals in India reports the lack of knowledge and awareness in this regard. ${ }^{13}$ A similar majority of the participants in our study had prior experience with researches and preferred checking their articles for plagiarism by using freely available online tools before sending it to a journal. Thus with research experience, the chances of an author publishing plagiarized work is reduced. Consistent with this finding, plagiarism is reported quite frequently in the early stages of a researcher's career ${ }^{14}$ whereas relatively fewer studies report such incidences in students of higher grades with more research experience. ${ }^{15}$ Furthermore, the study by Shirazi et al (2010) ${ }^{7}$ discussed herein also revealed a better understanding of self-plagiarism among faculty members in contrast to medical students due to differences in prior research experiences.

The participants' knowledge in our study was assessed with two sample paragraphs; one of which was plagiarized and the other was not. Even with the strong belief of an overwhelming majority of the interviewees that plagiarism is avoidable, some of them (especially the ones in their early stages of learning) still plagiarized unintentionally as was also seen in the study, ${ }^{16}$ while others justified it with the lack of an institutional review policy and considered it for short deadlines. Undeveloped authorial identity is speculated as a major cause of unintentional plagiarism. ${ }^{16}$ Considering review procedures for plagiarism cumbersome and a difficult task for the institutions, instructional interventions were developed for individuals; the beneficial effects of which in terms of knowledge to avoid plagiarism were re- ported in the study conducted on the students of London. ${ }^{16}$ Since most of the individuals in our study considered plagiarism as stealing, as reported in a previous research conducted in Saudi Arabia, ${ }^{17}$ they deemed it as a punishable offence. However, they still believed that beginners in the field of research should be given some leverage in this aspect.

Secondly, we found statistically significant differences in knowledge, attitudes, and practices between medical and non-medical students with medical students having more knowledge about research ethics and plagiarism. Thus, a majority of them could differentiate the plagiarized sample paragraph from the authentic one. A similar study with a slight difference in the choice of the subjects was conducted in Karachi, Pakistan by Shirazi et al in 2010, in which they compared the knowledge of medical students and faculty members and concluded little difference between the two groups. ${ }^{7}$ Rathore et al reported positive attitudes of the medical students towards plagiarism in their study conducted in Lahore, Pakistan in 2015. ${ }^{18}$ In this study, we found statistically significant differences between the attitudes and practices of medical and non-medical students towards plagiarism with a generally negative attitude among medical students towards the act of plagiarism, possibly as a result of greater experience in the field. Thus, significant emphasis was laid on the detailed discussion of plagiarism in research ethics. This coupled with the fact that a significant majority of these students considered plagiarism as stealing and did not justify plagiarism in case of short deadlines, meant that reported temptation to plagiarize was essentially lower than that analyzed in the other group. As an outcome, non-medical students were comparatively more inclined towards the practice of plagiarism with or without a reasonable explanation for doing so. These differences in attitudes between medical and non-medical students can perhaps be attributed to additional multiple factors. Firstly, medical students are more likely to be aware of both, the importance of ethics, due to medical schools focusing on bio-ethics to improve patient care, and the importance of research, as there is strong encouragement from faculty in medical schools. ${ }^{19,20}$ Secondly, the curriculum of medical schools in Pakistan has a specific focus on teaching research methodology which is bound to improve knowledge and hence, attitudes towards ethical practices. ${ }^{21}$ Thirdly, physicians in Pakistan are mostly under public employment and to advance through the ranks, a certain number of publications are required; therefore they are more likely to work with medical students enforcing better attitudes towards research ethics. Finally, there are dedicated private institutions which teach medical students how to conduct research properly such the Research Council of Pakistan, such institutions do not exist for other fields.

Our study has certain limitations which need to be considered. Since our study is based solely on undergraduate students in well-reputed universities of Karachi, accurate assessment of overall existent knowledge and attitudes towards plagiarism could not be made. This is because all the participants essentially belonged to the same age group and socioeconomic status with seemingly easier access to plagiarism detection tools. Also due to convenience sampling, students currently at the same academic level were assessed and professionally qualified researchers could not be included in our study hence, our population lacked diversity. We have reported only one aspect of research ethical misconducts that is plagiarism while there exist many others, which even though less prevalent, are still important to discuss and take care of. Some of these aspects include falsifi- 
Table 3. Comparative results of the study derived by using SPSS

\begin{tabular}{|c|c|c|c|c|}
\hline Questions & & $\begin{array}{l}\text { Medical } \\
\text { students } \\
(n=206)\end{array}$ & $\begin{array}{l}\text { Non-medical } \\
\text { students } \\
(n=179)\end{array}$ & $P$ value \\
\hline \multirow[t]{2}{*}{ Are you aware of the research ethics? } & Yes & $169(82 \%)$ & $119(66.5 \%)$ & \multirow{2}{*}{$P=0.001$} \\
\hline & No & $37(18 \%)$ & $60(33.5 \%)$ & \\
\hline \multirow[t]{2}{*}{$\begin{array}{l}\text { Have you heard about the term plagiarism? If yes, do you } \\
\text { understand this term? }\end{array}$} & Yes & $\begin{array}{c}194 \\
(94.2 \%)\end{array}$ & $159(88.3 \%)$ & \multirow[t]{2}{*}{$P=0.065$} \\
\hline & No & $12(5.8 \%)$ & $20(11.6 \%)$ & \\
\hline \multirow[t]{2}{*}{$\begin{array}{l}\text { Are you aware of the term referencing? If yes, do you believe in its } \\
\text { importance? }\end{array}$} & Yes & $\begin{array}{c}182 \\
(88.3 \%)\end{array}$ & $153(85.5 \%)$ & \multirow[t]{2}{*}{$P=0.135$} \\
\hline & No & $24(11.6 \%)$ & $26(14.5 \%)$ & \\
\hline \multirow{3}{*}{$\begin{array}{l}\text { Identify if it is plagiarized (authentic ie, not plagiarized paragraph } \\
\text { was given) }\end{array}$} & Yes & $35(17 \%)$ & $50(27.9 \%)$ & \multirow{3}{*}{$P=0.005$} \\
\hline & No & $\begin{array}{c}155 \\
(75.2 \%)\end{array}$ & $107(59.8 \%)$ & \\
\hline & Maybe & $16(7.8 \%)$ & $22(12.3 \%)$ & \\
\hline \multirow[t]{3}{*}{ Identify if it is plagiarized (plagiarized paragraph was given) } & Yes & $163(79.1 \%)$ & $104(58.1 \%)$ & \multirow{3}{*}{$P<0.001$} \\
\hline & No & $30(14.6 \%)$ & $50(27.9 \%)$ & \\
\hline & Maybe & $13(6.3 \%)$ & $25(14 \%)$ & \\
\hline \multirow[t]{2}{*}{$\begin{array}{l}\text { Do you think it is important to discuss issues like plagiarism in } \\
\text { research ethics? }\end{array}$} & Yes & $\begin{array}{c}201 \\
(97.6 \%)\end{array}$ & $164(91.6 \%)$ & \multirow{2}{*}{$P=0.01$} \\
\hline & No & $25(2.4 \%)$ & $15(8.4 \%)$ & \\
\hline \multirow[t]{2}{*}{ Do you consider self-plagiarism as plagiarism? } & Yes & $98(47.6 \%)$ & $82(45.8 \%)$ & \multirow[b]{2}{*}{$P=0.759$} \\
\hline & No & $\begin{array}{c}108 \\
(52.4 \%)\end{array}$ & $96(54.8 \%)$ & \\
\hline \multirow[t]{2}{*}{ Do you believe you work in a plagiarism free environment? } & Yes & $71(34.5)$ & $65(36.3 \%)$ & \multirow[b]{2}{*}{$P=0.749$} \\
\hline & No & $\begin{array}{c}135 \\
(65.5 \%)\end{array}$ & $114(63.7 \%)$ & \\
\hline \multirow[t]{2}{*}{ Do you believe plagiarism is justified for short deadlines? } & Yes & $46(22.3 \%)$ & $70(44.1 \%)$ & \multirow[b]{2}{*}{$P<0.001$} \\
\hline & No & $\begin{array}{c}160 \\
(77.7 \%)\end{array}$ & $100(55.9 \%)$ & \\
\hline \multirow{2}{*}{$\begin{array}{l}\text { Do you ever feel tempted to plagiarize because everyone else is } \\
\text { doing it? }\end{array}$} & Yes & $60(29.1 \%)$ & $94(52.5 \%)$ & \multirow{2}{*}{$P<0.001$} \\
\hline & No & $146(70.9 \%)$ & $85(47.5 \%)$ & \\
\hline \multirow[t]{2}{*}{ Do you think plagiarism can be avoided? } & Yes & $\begin{array}{c}184 \\
(89.3 \%)\end{array}$ & $148(82.7 \%)$ & \multirow[t]{2}{*}{$P=0.075$} \\
\hline & No & $22(10.7 \%)$ & $31(17.3 \%)$ & \\
\hline \multirow[t]{2}{*}{ Do you think that the authors who plagiarize deserve punishment? } & Yes & $169(82 \%)$ & $134(74.9 \%)$ & \multirow{2}{*}{$P=0.105$} \\
\hline & No & $37(18 \%)$ & $45(25.1 \%)$ & \\
\hline \multirow{2}{*}{$\begin{array}{l}\text { Do you think beginners in the field of research should be forgiven } \\
\text { for plagiarism since they're at the early stage of learning? }\end{array}$} & Yes & $143(143 \%)$ & $128(71.5 \%)$ & \multirow{2}{*}{$P=0.737$} \\
\hline & No & $73(63 \%)$ & $51(51 \%)$ & \\
\hline \multirow[t]{2}{*}{ Plagiarism is the same as stealing. Do you agree? } & Yes & $\begin{array}{c}195 \\
(94.7 \%)\end{array}$ & $147(82 \%)$ & $P<0.001$ \\
\hline & No & $11(5.3 \%)$ & $32(17.9 \%)$ & \\
\hline Do you have experience with researches? & Yes & $140(68 \%)$ & $95(53.1 \%)$ & $P=0 \cap 03$ \\
\hline & No & $66(32 \%)$ & $84(46.9 \%)$ & $r-0.000$ \\
\hline Have you ever plagiarized unintentionally due to lack of & Yes & $75(36.4 \%)$ & $111(62 \%)$ & \\
\hline knowledge and learnt about it later? & No & $\begin{array}{c}131 \\
(63.6 \%)\end{array}$ & $68(38 \%)$ & $P<0.001$ \\
\hline $\begin{array}{l}\text { Have you ever considered checking your articles for plagiarism } \\
\text { before sending it to a journal? }\end{array}$ & Yes & $\begin{array}{c}122 \\
(59.2 \%)\end{array}$ & $116(64.8 \%)$ & $P=0.293$ \\
\hline & No & $84(40.8 \%)$ & $63(35.2 \%)$ & \\
\hline Have you ever used freely available online plagiarism detection & Yes & $54(26.2 \%)$ & $84(46.9 \%)$ & $P<0001$ \\
\hline tools? & No & 152 & 95 (53.1\%) & $r-0.001$ \\
\hline
\end{tabular}




\begin{tabular}{|c|c|c|c|c|}
\hline Questions & & $\begin{array}{l}\text { Medical } \\
\text { students } \\
(\mathrm{n}=206)\end{array}$ & $\begin{array}{l}\text { Non-medical } \\
\text { students } \\
(n=179)\end{array}$ & $P$ value \\
\hline & & (73.8\%) & & \\
\hline \multirow{2}{*}{$\begin{array}{l}\text { Do you get your articles reviewed for plagiarism by the review } \\
\text { board of your institute before sending it to a journal? }\end{array}$} & Yes & $70(34 \%)$ & $80(44.7 \%)$ & \multirow{2}{*}{$P=0.036$} \\
\hline & No & $136(66 \%)$ & $99(55.3 \%)$ & \\
\hline \multirow{2}{*}{$\begin{array}{l}\text { Have you ever plagiarized because your institute does not have a } \\
\text { plagiarism policy? }\end{array}$} & Yes & $26(12.6 \%)$ & 65 (36.3\%) & \multirow[b]{2}{*}{$P<0.001$} \\
\hline & No & $\begin{array}{c}180 \\
(87.4 \%)\end{array}$ & 114 (63.7\%) & \\
\hline \multirow[t]{2}{*}{$\begin{array}{l}\text { Have you ever copied a friend's or a colleague's work with his } \\
\text { permission? }\end{array}$} & Yes & $\begin{array}{c}109 \\
(52.9 \%)\end{array}$ & 129 (72.1\%) & \multirow{2}{*}{$P<0.001$} \\
\hline & No & $97(47.1 \%)$ & $50(27.9 \%)$ & \\
\hline
\end{tabular}

cation, fabrication, misrepresentation, breach of confidentiality, etc.

Having said that, efforts should be taken to promote research on this topic with alterations in the interviewees' age and academic statuses so that diverse perspectives could be gathered about the knowledge and prevalence of plagiarism. The population under consideration should include different demographic groups such as people from socioeconomic backgrounds and institutes other than those already considered especially focusing on the researchers who have no knowledge or access to plagiarism detection software. However, the comparisons between the medical and non-medical students drawn in this study should also be extended further for additional insight into the possible reasons of differences in attitudes and practices between the two groups. Research department officials in colleges should be separately assessed to see if advanced learning and easier access to different research tools have had an impact on their attitude towards plagiarism. Since research ethics constitute a separate discipline which studies the norms and serves the aim of a research, these are vital, as adherence to these promote values that give rise to collaborative work which ultimately affects the success of a research. Thus, the prevalence of ethical misconducts of a study other than plagiarism should also be analyzed in further studies. Also, interviewee's opinion regarding the avoidance of plagiarism and other elements of ethical misconducts should be considered.

\section{CONCLUSIONS}

This study aimed at determining the knowledge, attitudes, and practices of an undergraduate student towards plagiarism, shows that a huge majority of individuals had proper knowledge of the terms plagiarism and referencing and realized their importance. This gave rise to a significantly negative attitude towards plagiarism in this group as shown by the approach considered towards researchers who plagiarize. However, the practice of plagiarism was prevalent in these individuals when they did not have the knowledge about research ethics which gives us the idea that majority of the researchers currently practicing plagiarism might be doing so because of the lack of knowledge. Further studies should assess this association which if proven true must be followed by an academic strategy aimed at raising proper awareness in researchers. Also, it was observed that medical and non-medical students had considerable differences in their opinions with medical students having a negative attitude towards plagiarism owing to their greater knowledge and experience with researches. Since academic integrity is important in making students more ethical in their profession, institutions must come together to generate a culture of integrity for the correction of student behaviors, especially, concerning ethical misconducts. Furthermore, institutions should provide their students with resources to screen their manuscripts for plagiarism before sending it to a journal. Emphasis on research ethics should be laid on in the undergraduate medical school curriculum which might decrease deliberate plagiarism. This shall contribute to more authentic and less questionable publications from the students.

Acknowledgements: This study was approved by the Institutional Review Board of Dow University of Health Sciences (DUHS).

Funding: None.

Competing interests: The authors have completed the Unified Competing Interest form at http://www.icmje.org/ coidisclosure.pdf (available on request from the corresponding author) and declare no conflict of interest.

\section{Correspondence to:}

\section{Mahrukh Muhammad Ali}

4th-year student of MBBS at Dow University of Health Sciences

Karachi

Sindh

Pakistan

mahrukhmuhammadali96@gmail.com 


\section{REFERENCES}

1. Teh EC, Paull M. Reducing the prevalence of plagiarism: A model for staff, students and universities. Issues Educ Res. 2013;23:283-298.

2. Marshall S, Garry M. NESB and ESB students' attitudes and perceptions of plagiarism. Int J Educ Integr. 2006;2:26-37. doi:10.21913/IJEI.v2i1.25

3. Fishman T. "We know it when we see it" is not good enough: Toward a standard definition of plagiarism that transcends theft, fraud, and copyright. 2009. htt p://ro.uow.edu.au/cgi/viewcontent.cgi?article=103 7 \&context=apcei. Accessed September 30, 2009.

4. Dhingra D, Mishra D. Publication misconduct among medical professionals in India. Indian J Med Ethics. 2014;11:104-107. doi:10.20529/ijme.2014.026

5. Ghias K, Lakho GR, Asim H, Azam IS, Saeed SA. Self-reported attitudes and behaviours of medical students in Pakistan regarding academic misconduct: A cross-sectional study. BMC Med Ethics. 2014;15(1):43. doi:10.1186/1472-6939-15-43

6. Abasi AR, Graves B. Academic literacy and plagiarism: Conversations with international graduate students and disciplinary professors. J Engl Acad Purposes. 2008;7(4):221-233. doi:10.1016/j.jea p.2008.10.010

7. Shirazi B, Jafarey AM, Moazam F. Plagiarism and the medical fraternity: A study of knowledge and attitudes. J Pak Med Assoc. 2010;60:269.

8. Stamatatos E. Intrinsic plagiarism detection using character n-gram profiles. In: Stein B, Rosso P, Stamatatos E, Koppel M, Agirre E, eds. SEPLN 2009 Workshop on Uncovering Plagiarism, Authorship, and Social Software Misuse (PAN 2009). ; 2009:38-46.

9. Rathore FA, Farooq F. Plagiarism detection softwares: Useful tools for medical writers and editors. J Pak Med Assoc. 2014;64:1329.

10. Gilmore J, Strickland D, Timmerman B, Maher M, Feldon D. Weeds in the flower garden: An exploration of plagiarism in graduate students' research proposals and its connection to enculturation, ESL, and contextual factors. Int J Educ Integr. 2010;6:13-28. doi:10.21913/IJEI.v6i1.673

11. Okonta P, Rossouw T. Prevalence of scientific misconduct among a group of researchers in Nigeria. Dev World Bioeth. 2013;13(3):149-157. doi:10.1111/ j.1471-8847.2012.00339.x
12. Farandos NM, Yetisen AK, Monteiro MJ, Lowe CR, Yun SH. Contact lens sensors in ocular diagnostics. Adv Healthc Mater. 2015;4(6):792-810. doi:10.1002/a dhm.201400504

13. Jain S, Saxena V, Hongal S, Jain M, Torwane N, Sharva V. Comparison of Opinion Referendum of Medical and Dental Postgraduates Towards Plagiarism in Bhopal-Central India. J Coll Physicians Surg Pak. 2015;25:514-518.

14. Martinson BC, Anderson MS, De Vries R. Scientists behaving badly. Nature. 2005;435(7043):737-738. doi:10.1038/435737a

15. Carnero AM, Mayta-Tristan P, Konda KA, et al. Plagiarism, Cheating and Research Integrity: Case Studies from a Masters Program in Peru. Sci Eng Ethics. 2017;23(4):1183-1197. doi:10.1007/s11948-01 6-9820-Z

16. Elander J, Pittam G, Lusher J, Fox P, Payne N. Evaluation of an intervention to help students avoid unintentional plagiarism by improving their authorial identity. Assess Eval High Educ. 2010;35(2):157-171. doi:10.1080/02602930802687745

17. Hosny M, Fatima S. Attitude of students towards cheating and plagiarism: University case study. J Appl Sci (Faisalabad). 2014;14(8):748-757. doi:10.3923/ja $\underline{\mathrm{s} .2014 .748 .757}$

18. Rathore FA, Waqas A, Zia AM, Mavrinac M, Farooq $F$. Exploring the attitudes of medical faculty members and students in Pakistan towards plagiarism: A cross sectional survey. PeerJ. 2015;3:e1031. doi:10.7717/pe erj.1031

19. Pallamparthy S, Basavareddy A. Knowledge, attitude, practice, and barriers toward research among medical students: A cross-sectional questionnaire-based survey. Perspect Clin Res. 2019;10(2):73-78. doi:10.4103/picr.picr 118

20. Moraes DW, Jotz M, Menegazzo WR, et al. Interest in research among medical students: Challenges for the undergraduate education. Rev Assoc Med Bras. 2016;62(7):652-658. doi:10.1590/1806-9282.62.07.652

21. Amgad M, Man Kin Tsui M, Liptrott SJ, Shash E. Medical Student Research: An Integrated MixedMethods Systematic Review and Meta-Analysis. Manalo E, ed. PLoS ONE. 2015;10(6):e0127470. doi:1 0.1371/journal.pone. 0127470 